\title{
Nature of Penicillin-Induced Growth Inhibition of Mycoplasma neurolyticum
}

\author{
D. N. WRIGHT \\ Naval Biological Laboratory, School of Public Health, University of California, Berkeley, California
}

Received for publication 6 August 1966

\begin{abstract}
When penicillin was added to cultures of Mycoplasma neurolyticum in amounts up to 1,000 units per ml, lag time and generation time were increased and the total population was reduced in proportion to the antibiotic concentration. Although growth suppression by penicillin was complete, the death rate was slow and linear over periods up to 12 days. Growth after induced lag was due to a decay in penicillin activity and was not the result of mutant selection. However, repeated transfer in media which contained increasing concentrations of penicillin resulted in normal growth of $M$. neurolyticum at penicillin levels as high as 1,000 units per ml. Penicillinase did not play a role in recovery from penicillin-induced lag, and the inactive penicillin molecule did not prevent normal growth of $M$. neurolyticum. Removal of penicillin from the medium by washing or penicillinase during the induced lag was immediately followed by normal growth of the organism. These results suggest a reversible antibiotic function for penicillin which prevents multiplication of the organism by means unrelated to cell wall formation.
\end{abstract}

The use of Mycoplasma neurolyticum as a model for study of the genus Mycoplasma led to the discovery by Hottle and Wright (9) that this organism is sensitive to penicillin levels as low as 40 units per $\mathrm{ml}$. The inhibition by penicillin of an organism lacking a cell wall has not been reported and is unique among species of $\mathrm{Myco}$ plasma to this species. The mechanism whereby penicillin prevents growth or division of grampositive organisms has been clearly demonstrated $(1,2,5,14,17,19)$ and is based upon the prevention of complete cell wall synthesis by the inhibited organism. Although $M$. neurolyticum has not been investigated as to its surface composition and may in the future be shown to have a wall-like covering, mycoplasmas are characteristically thought to be without a rigid cell wall structure (12). Therefore, this now classical concept of penicillin inhibitory action seemed inadequate to explain the results reported for $M$. neurolyticum. This investigation was undertaken to determine the effect of penicillin on $M$. neurolyticum and to gain an understanding of the possible mode of action of penicillin as a growth inhibitor of organisms which normally lack a cell wall.

\section{MATERIALS AND METHODS}

Organism and media. M. neurolyticum (Sabin type A), media used, culture procedures, and assessment of growth have already been described (9).
Assay of penicillin and penicillinase activity. By use of the method of Vaichulis and Doll (18), the penicillin activity of basic growth medium (BGM) incubated at $37 \mathrm{C}$ and containing 10,000 or 2,000 units of penicillin per $\mathrm{ml}$, was determined at $24-\mathrm{hr}$ intervals over a 7-day period. Penicillinase activity at $37 \mathrm{C}$ in BGM was determined by adding either $1,0.1$, or $0.01 \mathrm{mg}$ of penicillinase per $\mathrm{ml}$ to tubes containing 10 , 50 , or 100 units of penicillin per ml. At $1,10,30$, and $60 \mathrm{~min}, 2 \mathrm{ml}$ of the BGM penicillin-penicillinase mixture was removed and filtered through a Seitz filter; the penicillin activity of the filtrate was determined. The penicillin used in this study was benzylpenicillin $G$ obtained from Eli Lilly \& Co., Indianapolis, Ind. The penicillinase was from Riker Laboratories, Inc., Northridge, Calif.

\section{RESULTS}

The growth of $M$. neurolyticum in medium containing various amounts of penicillin is shown in Fig. 1. Levels of penicillin as low as 40 units per $\mathrm{ml}$ were effective in reducing the growth of this organism. The values of four growth parameters at various penicillin concentrations are shown in Table 1.

At concentrations of penicillin between 40 and 200 units per $\mathrm{ml}$, the most notable effect on growth of $M$. neurolyticum was a marked increase in the length of the lag time and an increased generation time. To a lesser extent, in- 


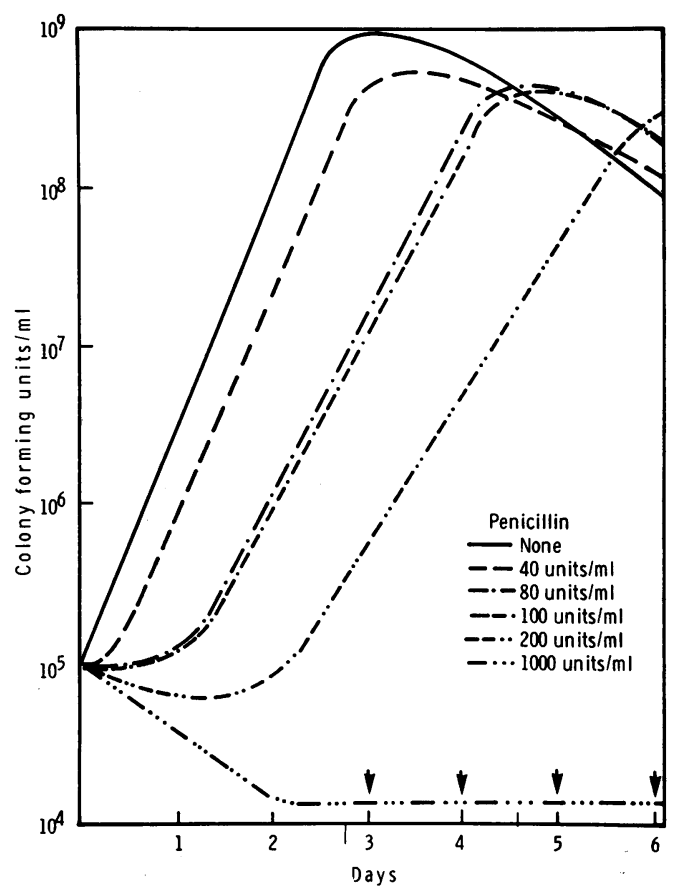

FIG. 1. Growth of Myoplasma neurolyticum at $37 \mathrm{C}$ in basic growth medium containing penicillin; $\boldsymbol{v}$ indicates number of colony-forming units was less than $10^{4} / \mathrm{ml}$.

TABLE 1. Effect of penicillin on various growth parameters of Mycoplasma neurolyticum

\begin{tabular}{r|c|c|c|c}
\hline Penicillin & Lag time & $\begin{array}{c}\text { Generation } \\
\text { time }\end{array}$ & $\begin{array}{c}\text { Time to } \\
\text { maximal } \\
\text { growth }\end{array}$ & $\begin{array}{c}\text { Maximal } \\
\text { no. of CFU/ } \\
\text { ml X!10 }\end{array}$ \\
\cline { 1 - 2 } units/ml & $h r$ & $h r$ & $h r$ & \\
0 & 0 & 4 & 54 & 9 \\
2 & 0 & 4 & 54 & 9 \\
10 & 0 & 4 & 54 & 9 \\
20 & 0 & 4 & 54 & 9 \\
40 & 7 & 5.7 & 78 & 5 \\
80 & 24 & 6.7 & 108 & 4 \\
100 & 26 & 6.9 & 114 & 4 \\
200 & 51 & 9 & 144 & 3 \\
1,000 & 156 & - & 10 (days) & $<1$ \\
\hline
\end{tabular}

${ }^{a} \mathrm{CFU}=$ colony-forming units.

creasing concentrations of penicillin produced a decrease in total growth and a delay in the time to attain maximal growth. Although not shown, a direct relationship between penicillin concentration and effect on the growth parameters was observed at all concentrations tested up to 1,000 units of penicillin per $\mathrm{ml}$.

Because of the increase in lag time with increasing concentrations of penicillin, it seemed likely that growth occurred only when the peni- cillin activity had declined below an inhibitory threshold concentration. Figure 2 shows the results of a 6-day titration of penicillin activity in sterile culture medium which was incubated at $37 \mathrm{C}$. There is a linear decrease in penicillin activity such that the time of increase in colonyforming units (CFU) correlates with a decrease in penicillin activity to less than 100 units per $\mathrm{ml}$.

The possibility that the outgrowth of culture after penicillin-induced lag included cells with an increased resistance to penicillin was investigated by using cells from cultures containing 200 units of penicillin per $\mathrm{ml}$ as inoculum for subsequent cultures containing 200 units of penicillin per $\mathbf{m l}$. Cells grown in medium containing penicillin had an increased resistance to growth inhibition by the antibiotic when subsequently inoculated into fresh medium containing penicillin. The growth rate of these cultures appeared to be slightly higher and the duration of their lag was appreciably shortened by this procedure.

To determine whether $M$. neurolyticum could be made to grow normally in the presence of inhibitory concentrations of penicillin, cells which were grown by stepwise transfer to various media containing up to 1,000 units per $\mathrm{ml}$ of penicillin in increments of 100 units per ml were subsequently used to inoculate media containing

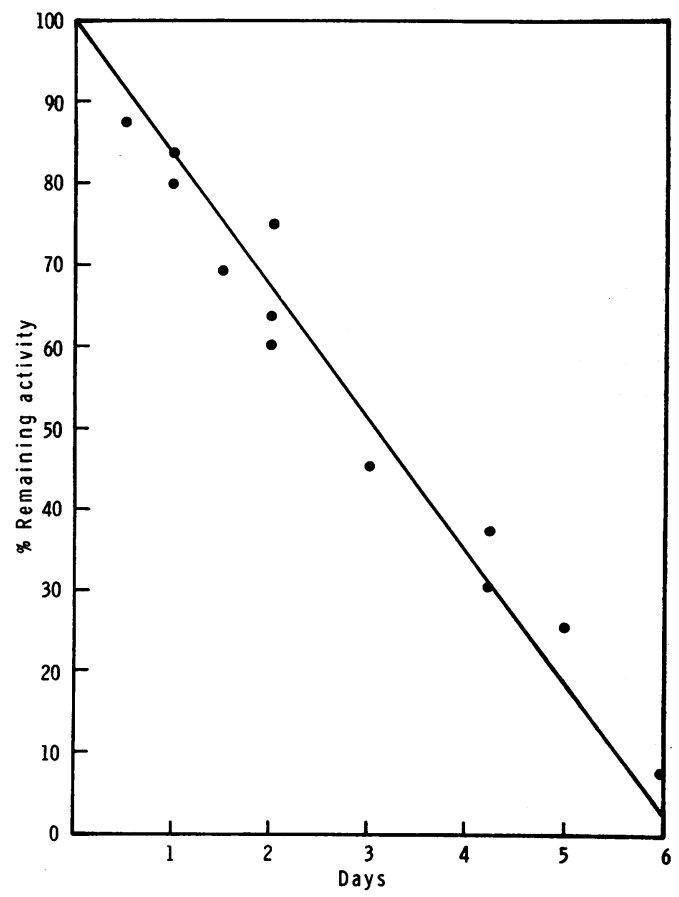

FIG. 2. Decay of penicillin activity at $37 \mathrm{C}$ in basic growth medium. 
40,200 , and 1,000 units of penicillin per $\mathrm{ml}$. The cells used for inoculation of these cultures were from a culture which contained 1,000 units of penicillin per $\mathrm{ml}$ and had grown to a maximal titer in 4 days instead of the normal 16 days reported by Hottle and Wright (9) for unadapted organisms. Figure 3 indicates that, although growth of adapted organisms in media containing penicillin was not as rapid as with a control culture without penicillin, the ability of the organism to withstand high levels of penicillin increased considerably after prolonged contact with the drug. It is significant, however, that such adaptability was not permanent, and reversion to complete penicillin sensitivity occurred after several passages in penicillin-free medium.

The prolonged growth lag, followed by nearly normal growth rates, and the fact that growth occurred only when the penicillin activity had diminished to less than 100 units per $\mathrm{ml}$ suggested that it might be possible to reverse the effects of penicillin during the induced lag period. To show reversibility of inhibition, an attempt was made to remove penicillin from the cells by washing with BGM. Duplicate 10-ml cultures in

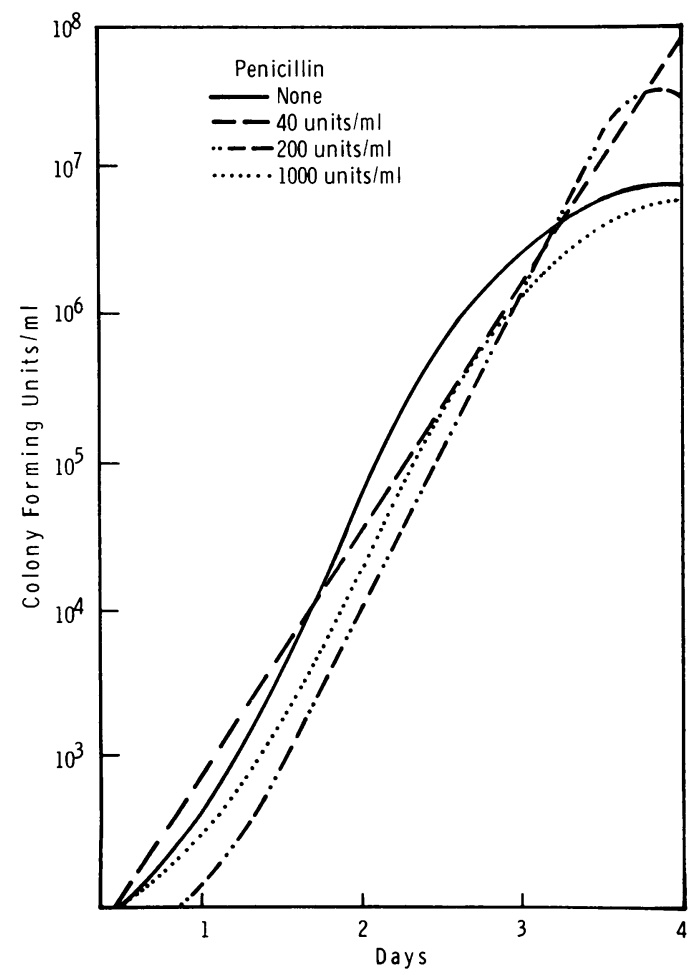

Fig. 3. Growth of Myoplasma neurolyticum in the presence of various concentrations of penicillin. The inoculum for each culture was from growth occurring in cultures containing 1,000 units of penicillin. 50-ml Sorvall centrifuge cups, containing various concentrations of penicillin, were inoculated with approximately $8 \times 10^{4} \mathrm{CFU} / \mathrm{ml}$ and were allowed to incubate for $48 \mathrm{hr}$ at $37 \mathrm{C}$. One of the duplicate cultures was centrifuged, washed with BGM, and resuspended in $10 \mathrm{ml}$ of fresh medium without penicillin. The number of CFU per $\mathrm{ml}$ was determined in both control and washed cultures (Fig. 4). The effect of penicillin could be considerably reduced by its removal; however, because of the long generation time of $M$. neurolyticum, it was not possible to determine whether recovery was instantaneous, or whether it occurred only upon completion of a gradual process of removal of penicillin from the cell after washing. Penicillin levels in the medium during these experiments were not determined.

To show more clearly the effect of penicillin removal, penicillinase was used to remove penicillin from inhibited cultures. Penicillinase per se, in concentrations up to $10 \mathrm{mg} \mathrm{ml}$, had no effect on the growth of $M$. neurolyticum, and a concentration of only $1 \mathrm{mg} \mathrm{ml}$ was found to inactivate 1,000 units of penicillin in BGM in less than 20 min at $37 \mathrm{C}$. Duplicate cultures containing various concentrations of penicillin were incubated for $24 \mathrm{hr}$ at $37 \mathrm{C}$ and titered for CFU. Penicillinase $(1 \mathrm{mg} / \mathrm{ml})$ was added to one tube of each duplicate set. The cultures were incubated for $30 \mathrm{~min}$ and again titered. The number of CFU was determined over a period of 6 days. The results (Fig. 5) indicate that after enzymatic removal of penicillin growth rapidly resumed, thus showing the completely reversible nature of the inhibition.

The reversibility of the penicillin inhibition of $M$. neurolyticum at drug levels as high as 1,000 units $\mathrm{ml}$ was demonstrated by growth of the cultures after a prolonged lag time during which no viable cells could be demonstrated. This observation led to an attempt to determine whether the inactivated cells were surviving penicillin treatment, or whether the cells died with only a few (less than 10 per $\mathrm{ml}$ ) surviving. Samples were removed at intervals during the induced lag phase from cultures with different concentrations of penicillin and were subjected to the following procedures: dilution in PPLO Broth (Difco) with CFU determination on agar plates; CFU determinations after dilution in PPLO Broth containing $5 \mathrm{mg}$ of penicillinase per ml; CFU determination on agar plates containing $10 \mathrm{mg}$ of penicillinase per $\mathrm{ml}$; CFU determinations on agar plates held at $4 \mathrm{C}$ for 24 hr prior to incubation.

If $M$. neurolyticum lies "dormant" without a marked decrease in viability, recovery of the 
cells should immediately follow the removal of penicillin, and the initial viable counts should be near the inoculum value and greater than for those cultures where the penicillin was not removed. However, if a period of time allowing for diffusion of penicillin from the cells is necessary, then those samples held at $4 \mathrm{C}$ for $24 \mathrm{hr}$ should show a significant increase in the number of viable cells recovered. Table 2 shows that there was no difference in the number of recoverable CFU per ml by any of the procedures attempted. These results suggest that, in fact, cell death does occur in the presence of penicillin, and growth, occurring after decay of penicillin activity, is initiated from a previously inhibited decreased population. A diffusion period does

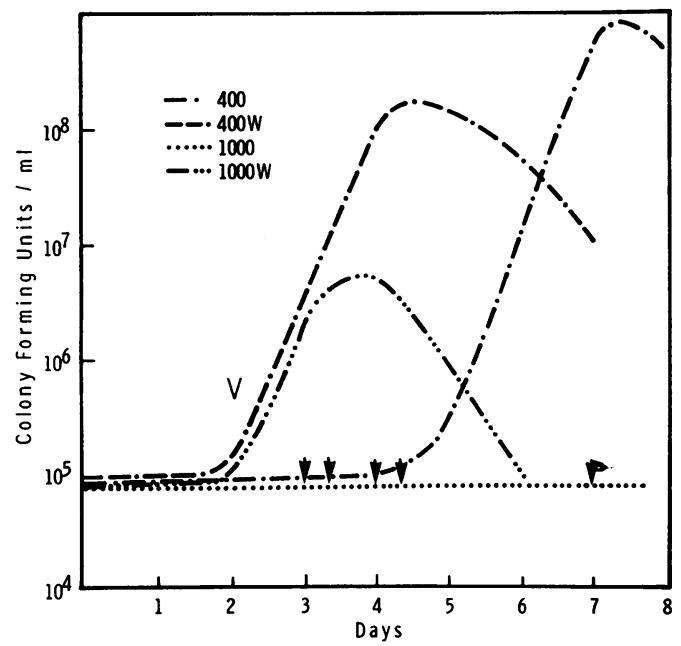

FIG. 4. Effect of removal of penicillin during the induced lag phase by washing with basic growth medium; $\checkmark$ denotes time of washing; penicillin concentrations are indicated in units per $\mathrm{ml}$ and washed cultures are designated $W ; \boldsymbol{V}$ indicates colony-forming units less than $10^{5}$. not enhance recovery of $M$. neurolyticum after penicillin treatment. Death, however, is not rapid, and there is significant survival of $M$. neurolyticum suspended in BGM at $37 \mathrm{C}$ over a 6-hr period at levels of penicillin as high as 4,000 units per ml (Fig. 6).

\section{Discussion}

The suppression-outgrowth phenomenon occurring at all penicillin concentrations between 40 and 1,000 units per $\mathrm{ml}$ suggested a threshold for the penicillin inhibition of $M$. neurolyticum at about 40 units per $\mathrm{ml}$. However, because of the normally slow growth rate, the apparent

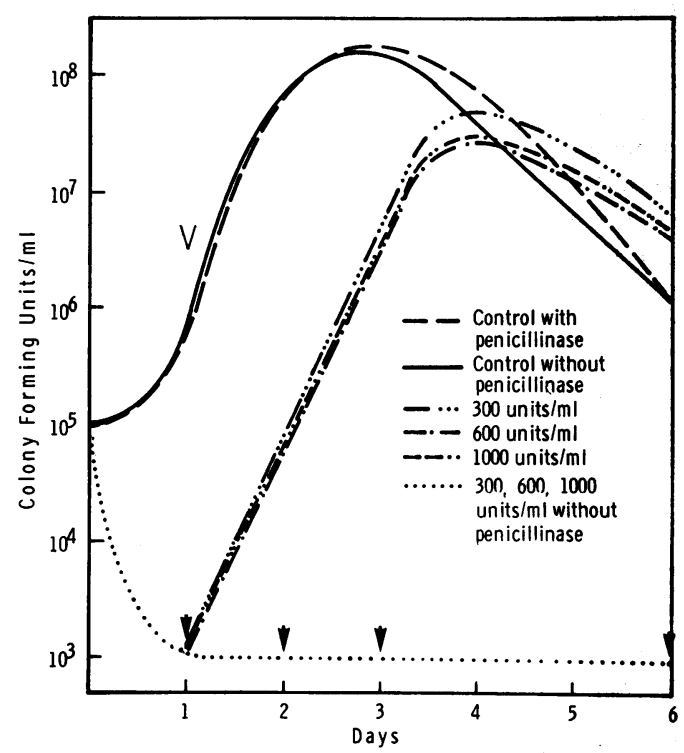

FiG. 5. Growth of Mycoplasma neurolyticum after removal of inhibiting concentrations of penicillin by the addition of $1.0 \mathrm{mg} / \mathrm{ml}$ of penicillinase; $\vee$ denotes time of penicillinase addition; $\checkmark$ indicates colony-forming units less than $10^{3}$.

TABLE 2. Effect of 30-hr contact with penicillin on the viability of Mycoplasma neurolyticum as demonstrated by four methods of recovery

\begin{tabular}{|c|c|c|c|c|c|}
\hline \multirow{2}{*}{ Methods of assay } & \multicolumn{5}{|c|}{$\begin{array}{c}\mathrm{CFU}^{a} / \mathrm{ml} \text { recovered after } 30 \text {-hr contact with various concentrations } \\
\text { of penicillin }\end{array}$} \\
\hline & None & 40 & 100 & 1,000 & 10,000 \\
\hline $\begin{array}{l}\text { On BGM }{ }^{c} \text { agar } \ldots \ldots \ldots \ldots \\
\text { After dilution in penicillinase }(5 \mathrm{mg} / \mathrm{ml}) \ldots \ldots \\
\text { On } \mathrm{BGM}^{c} \text { agar with penicillinase }(10 \mathrm{mg} / \mathrm{ml}) \ldots \\
\text { Held at } 4 \mathrm{C} \text { on agar for } 24 \mathrm{hr} \text { prior to incuba- } \\
\quad \text { tion. } \ldots \ldots \ldots \ldots \ldots \ldots \ldots \ldots \ldots \ldots \ldots \ldots \ldots \ldots \ldots\end{array}$ & $\begin{array}{l}2 \times 10^{8} \\
8 \times 10^{7} \\
8 \times 10^{7} \\
1 \times 10^{8}\end{array}$ & $\begin{array}{l}4 \times 10^{7} \\
5 \times 10^{7} \\
4 \times 10^{7} \\
4 \times 10^{7}\end{array}$ & $\begin{array}{l}2 \times 10^{6} \\
2 \times 10^{6} \\
2 \times 10^{6} \\
2 \times 10^{6}\end{array}$ & $\begin{array}{l}1 \times 10^{4} \\
1 \times 10^{4} \\
2 \times 10^{4} \\
1 \times 10^{4}\end{array}$ & $\begin{array}{l}3 \times 10^{4} \\
4 \times 10^{4} \\
7 \times 10^{8} \\
3.5 \times 10^{4}\end{array}$ \\
\hline
\end{tabular}

${ }^{a} \mathrm{CFU}=$ colony-forming units.

$b$ Penicillin in units per milliliter.

${ }^{c} \mathbf{B G M}=$ basic growth medium. 


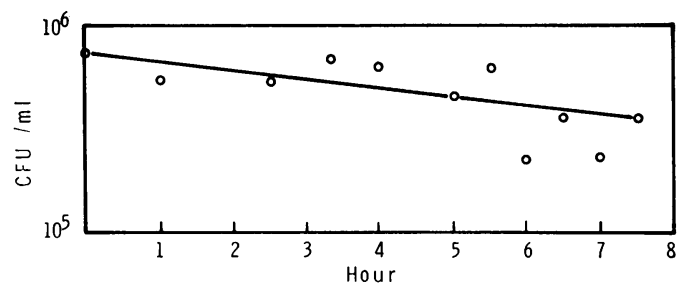

FIG. 6. Viability of Mycoplasma neurolyticum at $37 \mathrm{C}$ in basic growth medium containing 40,000 units of penicillin per $\mathrm{ml}$. CFU = colony-forming units.

inhibition-threshold effect of penicillin may in fact represent an inability to measure growth rate changes brought on by low (less than 40 units per $\mathrm{ml}$ ) concentrations of penicillin. The direct correlation (Table 1) between penicillin concentration above 40 units per $\mathrm{ml}$ and inhibition suggests that any growth inhibition at antibiotic concentrations below this level would also be linear.

The data suggest that outgrowth after lag is due to a decrease in penicillin activity. The fact that cells recover ability to grow in penicillincontaining media at a predictable time, concomitant with or after decay of penicillin, indicates that penicillinase, if produced by these organisms, is not a factor in their recovery from penicillin inhibition, since no decrease in lag time below that expected from normal decay in penicillin activity occurred.

That growth after recovery from penicillininduced lag was approximate to growth in control cultures suggested that only active penicillin is capable of suppressing growth of $M$. neurolyticum. This observation is further supported by the normal growth of $M$. neurolyticum after penicillinase treatment of drug-inhibited cultures.

Several attempts to isolate nonreversible penicillin-resistant mutants after prolonged contact between the organism and penicillin were without success. However, a stepwise transfer of cultures to increasing concentrations of penicillin produced organisms which were thereafter capable of growing normally in high levels of penicillin (Fig. 3). This increased penicillin resistance is not well understood but may represent a shift in the metabolic functions of the cell in order to compensate for growth under adverse conditions. The remarkable hardiness and apparent plasticity of mycoplasmas have been noted previously (9).

Recent studies $(13,14,17,19)$ have elucidated a mechanism of penicillin action in gram-positive cocci by which penicillin prevents cross-linking of acetyl-muramic-polypeptide units of cell walls, with subsequent osmotic instability resulting in cell destruction. Fitz-James and Hancock (7) have recently given visual evidence of the accumulation of fiberlike processes, presumably acetyl-muramic-peptide wall material, in Bacillus megaterium during treatment with penicillin. However, the mycoplasmas lack, and presumably do not need, a cell wall, and studies to show amino sugar or muramic acid components have been without success in other mycoplasmas (11, 15). Studies in our laboratory (unpublished data) have shown that $M$. neurolyticum is resistant to lysozyme and presumably does not have a grampositive type cell wall. However, Domermuth et al. (6) noted that the cell membrane of $M$. neurolyticum was about $25 \mathrm{~A}$ thicker than the cell membranes of other mycoplasmas, and another study (16) has shown a resistance to osmotic lysis by $M$. neurolyticum greater than for most other mycoplasmas, a fact which suggests the possibility of a wall-type structure in this organism. Further studies to confirm the composition of the surface structure of $M$. neurolyticum are in progress. The possibility that penicillin may be acting competitively with some unknown metabolite was considered because of the linearity of the dose-inhibition response. However, the linear decrease in penicillin activity suggested that what appears to be a competitive system may be a reversible noncompetitive effect, whereby penicillin is inhibitory regardless of metabolite concentration; growth occurs only after penicillin decays to such low levels that inhibition cannot be demonstrated.

The removal of penicillin from these cells by washing and the susceptibility of penicillin in culture to the action of penicillinase suggests that the site of penicillin action on this organism is at the cell surface such that the $\beta$ lactam ring of penicillin is still available to the action of penicillinase. Cooper (3) showed that, in grampositive bacteria, penicillin is bound to a lipid of the cell membrane, and other studies $(1,2,5)$ have shown a close relationship between membrane lipid components and cell wall synthesis. It is possible that the binding of penicillin to $M$. neurolyticum occurs in a manner similar to the binding on the membrane surfaces of the bacteria. However, just what effect the binding of penicillin would have on the membrane surfaces of $M$. neurolyticum is unclear.

The effects which penicillin may have on cells other than the inhibition of cell wall synthesis are too often overlooked. Cooper (4) suggested that the initial action of penicillin may be to disorganize some function of the osmotic barrier of the cell, and Gale and Taylor (8) showed active transport of amino acids to be diminished by the presence of penicillin, whereas Hunter and Baker (10) showed the development of 
instability to inorganic ions when penicillin was added to the medium. To what extent these observed mechanisms of inhibition function in penicillin inhibition of $M$. neurolyticum is not known. Thus, although Wise and Park (19) suggest that the sensitivity to penicillin of rickettsia and of large viruses is an indication that the penicillininhibited cell wall cross-linking reaction occurs in these organisms, the studies reported herein indicate that this is not the only possibility and that other inhibitory mechanisms may function in the viruses and rickettsia, as well as in Mycoplasma. Certainly, if it can be shown that, in fact, $M$. neurolyticum lacks even a rudimentary cell wall, then an explanation for penicillin action other than cell wall inhibition must be forthcoming.

\section{ACKNOWLEDGMENT}

The technical assistance of Virginia G. Rimer is gratefully acknowledged.

This investigation was sponsored by the Office of Naval Research under a contract with the Regents of the University of California.

\section{Literature Citrd}

1. Anderson, J. S., M. Matsuhashi, M. A. Haskin, AND J. L. STrominger. 1965. Lipid-phosphoacetyl muramyl-pentapeptide and lipid-phosphodisaccharide-pentapeptide: presumed membrane transport intermediates in cell wall synthesis. Proc. Natl. Acad. Sci. U.S. 53:881889.

2. Anderson, J. S., AND J. L. Strominger. 1965. Isolation and utilization of phospholipid intermediates in cell wall glycopeptide synthesis. Biochem. Biophys. Res. Commun. 21:516-521.

3. COOPER, P. D. 1954. The association of the penicillin-binding component of Staphylococcus aureus with a lipid fraction. J. Gen. Microbiol. 10:236-245.

4. COOPER, P. D. 1955. The site of action of penicillin: Some changes in Staphylococcus aureus during the first two hours growth in penicillin media. J. Gen. Microbiol. 13:22-38.

5. Dietrich, C. P., M. Matsuhashi, and J. L. STROMINGER. 1965. Glycerol diphosphate disaccharide-pentapeptide: A functional group of the lipid intermediate in cell wall glycopeptide synthesis. Biochem. Biophys. Res. Commun. 21:619-623.

6. Domermuth, C. H., M. H. Nielsen, A. E. FrEUNDT, AND A. BIRCH-ANDERSEN. 1964.
Ultrastructure of Mycoplasma species. J. Bacteriol. 88:727-744.

7. FITZ-JAMES, P., AND R. HANCOCK. 1965. The initial structural lesion of penicillin action in Bacillus megaterium. J. Cell Biol. 26:657-667.

8. Gale, E. F., AND E. S. TAYlor. 1947. The action of penicillin in preventing the assimilation of glutamic acid by Staphylococcus aureus. J. Gen. Microbiol. 1:314-326.

9. HotTLE, G. A., AND D. N. WRIGHT. 1966. Growth and survival of Mycoplasma neurolyticum in liquid medium. J. Bacteriol. 91:1834-1839.

10. Hunter, T. H., and K. T. BaKer. 1949. The action of penicillin on Bacillus subtilis growing in the absence of amino acids. Science 110:423425.

11. KANDLER, V. O., AND C. ZeheNDER. 1957. Über das Vorkommen von E-Diaminopimelinsäure bei verschiedenen L-Phasentypen von Proteus vulgaris und bei den pleuropneumonieähnlichen Organismen. Z. Naturforsch. 12b: 725-728.

12. KIIENEBERGER-NoBeL, E. 1962. Pleuropneumonialike organisms, (PPLO): Mycoplasmataceae. Academic Press, Inc., New York.

13. Martin, H. H. 1964. Composition of the mucopolymer in cell walls of the unstable and stable L-form of Proteus vulgaris. J. Gen. Microbiol. 36:441-450.

14. Meadow, P. M., J. S. Anderson, and J. L. STROMINGER. 1964. Enzymatic polymerization of UDP-acetylmuramyl L-Ala $\cdot$ D-Glu.L-lys $\cdot$ DAla.D-Ala and UDP-acetylglucosamine by a particulate enzyme from Staphylococcus aureus and its inhibition by antibiotics. Biochem. Biophys. Res. Commun. 14:382-387.

15. Plackett, P. 1959. On the probable absence of "mucocomplex" from Mycoplasma mycoides. Biochim. Biophys. Acta 35:260-262.

16. Razin, S., AND M. Argaman. 1963. Lysis of mycoplasma, bacterial protoplasts, spheroplasts and $L$ forms by various agents. J. Gen. Microbiol. 30:155-172.

17. Strominger, J. L., J. T. Park, AND R. E. ThompSON. 1959. Composition of the cell wall of Staphylococcus aureus: Its relation to the mechanism of action of penicillin. J. Biol. Chem. 234:3263-3268.

18. Vaichulis, E. M. K., AND J. P. Doll. 1959. Instability of penicillin in Dubos media. Am. Rev. Respirat. Diseases 80:262-263.

19. Wise, E. M., AND J. T. PARK. 1965. Penicillin: Its basic site of action as an inhibitor of a peptide cross-linking reaction in cell wall mucopeptide synthesis. Proc. Natl. Acad. Sci. U.S. 54:7581. 